Abstracta Iranica Abstracta Iranica

Revue bibliographique pour le domaine irano-aryen

Volume 25 | 2004

Comptes rendus des publications de 2002

\title{
Les messagers volants en terre d'islam. Paris, C.N.R.S. Éditions, 2002, 345 p., bibl., index.
}

Jean-Pierre Digard

\section{(2) OpenEdition}

1 Journals

Édition électronique

URL : http://journals.openedition.org/abstractairanica/4392

DOI : 10.4000/abstractairanica.4392

ISSN : 1961-960X

\section{Éditeur :}

CNRS (UMR 7528 Mondes iraniens et indiens), Éditions de l'IFRI

\section{Édition imprimée}

Date de publication : 15 mai 2004

ISSN : 0240-8910

\section{Référence électronique}

Jean-Pierre Digard, «Les messagers volants en terre d'islam. Paris, C.N.R.S. Éditions, 2002, 345 p., bibl., index. », Abstracta Iranica [En ligne], Volume 25 | 2004, document 117, mis en ligne le 15 mars 2006, consulté le 25 septembre 2020. URL : http://journals.openedition.org/abstractairanica/4392 ; DOI : https://doi.org/10.4000/abstractairanica.4392

Ce document a été généré automatiquement le 25 septembre 2020.

Tous droits réservés 


\title{
Les messagers volants en terre d'islam. Paris, C.N.R.S. Éditions, 2002, 345 p., bibl., index.
}

\author{
Jean-Pierre Digard
}

1 Les pigeons font recette! Après Le combat du colombophile de l'ethnologue A. Goushegir en 1997 (voir Abs. Ir. 20-21, 1997-1998, c.r. n 922), voici un ouvrage d'historien orientaliste sur la colombophilie en Islam.

2 Dans la première partie, l'A. nous invite à un voyage dans le temps - du Moyen-Orient pré-islamique à nos jours - et dans l'espace - de l'Iran à l'Espagne musulmane -, à travers les pratiques d'élevage (pigeonniers, alimentation, sélection, éducation), de commerce et d'utilisation des pigeons, principalement pour la poste, mais aussi pour les jeux aériens (de mauvaise réputation, comme dans l'Iran d'aujourd'hui). La seconde partie consiste en un recueil d'extraits de textes originaux traduits, illustrant différents aspects de la poste aérienne. Une très importante bibliographie (500 titres), un index des noms propres, trois cartes et huit illustrations complètent l'ensemble.

3 Il y a donc là un énorme travail de lecture, de dépouillement de sources et de regroupement d'informations éparses, mais qui n'est guidé par aucune problématique et qui ne débouche sur aucune réflexion d'ensemble ni perspective. Par ailleurs, la matière du livre apparaît trop morcelée entre un grand nombre de chapitres souvent très courts; du coup, la structure de l'ensemble reste quelque peu opaque. Enfin, la fonction d'acheminement des messages est privilégiée, au détriment d'autres usages : jeu (évoqué uniquement sur le mode péjoratif), ornement, agriculture (guano), consommation de chair... - et c'est dommage ! L'A. s'excuse presque de s'être intéressé à un sujet inhabituel chez les orientalistes et d'avoir adapté «son style au sujet pour rendre agréable la lecture de son œuvre» (p. VIII). On frémit à l'idée de que ce livre aurait pu être s'il s'était agi d'orientalisme véritable! 
INDEX

Thèmes : 4.0. Généralités

\section{AUTEURS}

JEAN-PIERRE DIGARD

CNRS - Paris 